\title{
Usable and Accessible Tourism Websites for Children: a Case Study of a Naturalistic Oasis
}

\author{
Antonina Dattolo ${ }^{1}$, Chiara De March ${ }^{2}$, and Flaminia L. Luccio ${ }^{3}$ \\ 1 SASWEB Lab, DMIF, University of Udine, Gorizia, Italy \\ antonina.dattolo@uniud.it \\ 2 Università Ca' Foscari Venezia, Venezia, Italy \\ 855411@stud.unive.it \\ 3 DAIS, Università Ca' Foscari Venezia, Venezia, Italy \\ luccio@unive.it
}

\begin{abstract}
The children's use of technology is increasing year by year and recent statistics show that children receive their first smartphone and autonomously navigate the Web when they are 10.3 years old (on average). Nevertheless, while the number of tourism packages for families with children grows, the number of websites that can be directly visited by children is small; more relevant, is the number of tourism applications developed for children. This paper discusses the design of usable and accessible websites for children, and proposes, as a case study, our experience on a dedicated section of the tourism website of a Naturalistic Oasis located close to Treviso, in Italy.
\end{abstract}

\section{Introduction}

A recent study, conducted in 2016 by the Influence Central [12], revels interesting statistics about the use of technologies by children in North America: children start receiving their first smartphone at 10.3 years of age, and they use it mainly for texting people and parents even in the same environment, e.g., same room, same building, etc.. These tools have become a sort of their own physical extension. During trips, tablets are in $55 \%$ of the cases the preferred entertainment tools, then phones in $45 \%$ of cases.

Regarding the access to Internet, the parents tend to be more permissive than in the past: only $76 \%$ of them impose strict limits on the independent use of the connection, compared to $85 \%$ in 2012 .

An interesting survey, conducted online in 2016 by the Erikson Institute, shows that in the United States even children below 6 years of age have a strong contact with technologies: parents reported that $85 \%$ of their children had a contact with television, tablets, smartphones, and computers on a daily base for up to two hours [11].

On the basis of these facts, two new challenges open up for the tourism:

- for tourism companies, as creating new digital cultural and tourism material addressed also for young users might be a winning strategy when the tourism 
destinations are devoted to families or schools. Tourism websites should provide recreational and educational material personalised to children, and are meant both to enhance the cultural and naturalistic heritage, and also to support practical and informative material for the tourism experience. Children will not be clients of the tourism experience, they will not be part of an economic exchange, but will be direct consumers. An involved and happy child will improve the tourism experience of the whole family and parents will become satisfied clients.

Different studies show how children may influence the choice of a tourism activity [17]. A child that enjoyed the website may ask the parents to visit the described place, and in turn also a parent may find in this nice website a sign of attention to the recreational and educational needs of a child, and thus a better quality of the proposed tourism experience.

- while dealing with educational tourism, for which the target consumers are students at school. Proposing interesting and well structured material online may be interesting to improve the didactical experience in class before, and after the tourism tour, and may also increment the interest of teachers, thus improving the competitiveness of the related tourism location.

Nevertheless, while the number of tourism packages for families with children and accessible tourism locations for children grows (see for example Pantou.org), the number of usable and accessible (U\&A) tourism websites for children is still small; more relevant is the number of tourism apps developed for children, such as [1] and [3], which are designed to entertain children in an intelligent and cultural way, encouraging them to ask questions and to think.

In the meantime, the Advocate for Children and Young People strives to maintain conformance to W3C's Web Content Accessibility Guidelines (WCAG); the UNTWO (World Tourism Organization) and the ENAT (European Network for Accessible Tourism) emphasise the relevant role of an inclusive Web design for tourism.

In this paper, we would like present our experience and work in designing and realising a section (for children) of the tourism website of a naturalistic oasis, called Oasi Cervara, close to the city of Treviso, in the North of Italy.

The paper is organised as follows: Section 2 introduces the concepts of usability and accessibility, explores the state of art and related work regarding the realisation of a tourism website for children, and proposes general guidelines for its development. Section 3 presents our case study, focused on a U\&A tourism, children-friendly website. Section 4 describes our experimental results, and finally Section 5 ends the paper with a look to future work.

\section{Website usability and accessibility}

Usability and accessibility are closely related and they overlap significantly; in the design of a website is effective to address them together. Following the definitions provided in [20]: usability is about designing products to be effective, 
efficient, and satisfying, while accessibility addresses discriminatory aspects, including people with age-related impairments. In this paper, we consider only this aspect of the accessibility. For general accessibility, guidelines we refer the reader to $[16]$.

\subsection{State of art}

Making U\&A for children a website that already owns these features for adults does not just consist in adding some colours, puppets and in eliminating or simplifying actions that adults consider difficult [18]. The same considerations apply for children of different ages, as older children show more experience than younger ones. This is the result of an interesting study that was conducted in 2010 by Jacob Nielsen using two rounds of testing: the first on 27 sites with 55 children, aged 6-11 in 2001; the second on 29 sites with 35 children, aged 3-12 years in 2010 [15].

Both studies, conducted at 9 years of distance, provide similar results with the only difference that the early exposure to computers has anticipated the abilities that children showed around $6-8$ years to $3-5$ years.

In [15], the author addresses different key features that have to be taken into consideration while developing sites for users aged 3-12 years. Note that, other guidelines have also been proposed for teenagers [14]. For users in the age range $3-12$, the first thing is to divide them in three groups young (3-5), mid-range (68 ), and older (9-12), as following specific guidelines for each group improves the user experience. Then, it is important to keep in mind that adults and children have different needs/perceptions.

From a usability study conducted in [13], it emerges the importance of providing a simple but funny name to the site to attract the child's attention. Also the related link should be easily memorised for future visits. The initial impression is also very important as it affects the whole user experience [18]. Moreover, during navigation, the user wants to have a full control of the site in order to be gratified, thus the navigational structure should be similar on each page of the site and should be easy to follow [19]. The search for items should be simple and direct [13]. Moreover, children want instant feedback for every action they make [21]. Having technical limitations provided, e.g., by the need to install plugins or update software, or by the access to old desktops/laptops, etc. may negatively affect the user experience. The same holds for mistakes that should be easily recovered from, or for promotional content that typically attracts the child but at the same time distances him from the site. To be enjoyable for a child, the site should offer entertainment such as games or interactive material. Personalisation of colour choices, graphical devices and animations is also considered important [13]. The text should be easy and succinct, at an appropriate readability level for the age range, colors should be bright and with a good contrast, the background should be colourful and not white [13]. It should still be clear which elements of the site are interactive and which are not $[4,8,21]$. 
Table 1: Topics of interest of the children's websites.

\begin{tabular}{|l|c|c|c|c|c|c|c|c|}
\hline Website / Feature & Animals & Badges & Coloring & Didactic activities & Games & Quizzes & Reading & Videos \\
\hline \hline PBS Kids & & & & $\sqrt{ }$ & $\sqrt{ }$ & $\sqrt{ }$ & $\sqrt{ }$ & $\sqrt{ }$ \\
\hline Sesame Street & & & $\sqrt{ }$ & $\sqrt{ }$ & $\sqrt{ }$ & & & $\sqrt{ }$ \\
\hline Starfall & $\sqrt{ }$ & & & $\sqrt{ }$ & $\sqrt{ }$ & & $\sqrt{ }$ & \\
\hline CoolMath4kids & & $\sqrt{ }$ & & $\sqrt{ }$ & $\sqrt{ }$ & $\sqrt{ }$ & & \\
\hline MakeMeGenius & $\sqrt{ }$ & & & $\sqrt{ }$ & $\sqrt{ }$ & $\sqrt{ }$ & $\sqrt{ }$ & $\sqrt{ }$ \\
\hline National Geographic Kids & $\sqrt{ }$ & $\sqrt{ }$ & & $\sqrt{ }$ & $\sqrt{ }$ & $\sqrt{ }$ & & $\sqrt{ }$ \\
\hline Fun Brain & & $\sqrt{ }$ & & $\sqrt{ }$ & $\sqrt{ }$ & & $\sqrt{ }$ & $\sqrt{ }$ \\
\hline Nick Jr. & & & $\sqrt{ }$ & $\sqrt{ }$ & $\sqrt{ }$ & & $\sqrt{ }$ & $\sqrt{ }$ \\
\hline Disney Jr. & & $\sqrt{ }$ & $\sqrt{ }$ & $\sqrt{ }$ & $\sqrt{ }$ & & & $\sqrt{ }$ \\
\hline Highlights for Kids & & & $\sqrt{ }$ & $\sqrt{ }$ & $\sqrt{ }$ & $\sqrt{ }$ & $\sqrt{ }$ & $\sqrt{ }$ \\
\hline Total & $30 \%$ & $40 \%$ & $40 \%$ & $100 \%$ & $100 \%$ & $50 \%$ & $60 \%$ & $80 \%$ \\
\hline
\end{tabular}

\subsection{Related Work and Guidelines}

The number of tourism websites for children is still small. Very recently, the Independent published a list of the 50 best travel websites [2]: it appears evident that all of them directly address adults and only indirectly children. A recent list of the 20 of the best free and fun educational websites for children [10] provides an idea of the widest topics of interest of the current portals dedicated to children. In Table 1 we list the 10 websites that apply U\&A guidelines and provide us an idea of the topics, considered appealing for children. We can note that the topics of interest may be considered general modalities for capturing the attention of the children; furthermore, these websites share general guidelines regarding the graphical layout, the navigation structure, the used language and the user model. Keeping in mind the common features of these websites, the previous observations that we mainly collected from [15], but also from [4, 6, 5, $7,8,13,18,19,21]$, we provide a list of general guidelines for a U\&A tourism website:

- The design and the structure should be simple, clear and predictable; the content focused on the objectives of the website. A fun name/logo should grab the user attention; the URL should be a predictable one. The information should be redundant, and a graphical visual interface should contain a copious use of pictures (drawings, photographs, symbolic images), easy to understand. The text should go with pictures. It should be clear, simple, and short; should be in a big font (14 characters points for younger and 12 points for older children), in plain Sans-serif style (e.g., Verdana), with bright colours and a good contrast. Headings and titles should be used.

The interface should be responsive and perceivable, for enabling the use of screen readers. To avoid: background sounds, moving text, blinking images and horizontal scrolling.

- Navigation should be consistent, similar in every page/section, and propose a simple and logical structure of navigation, also using navigation buttons at 
the top and the bottom of the page, and back/forward buttons. The website should be equipped with search engines.

- The website should engage the users, providing them entertaining, quick to judge (standard), clear, consistent, controllable, instantly gratifying, with feedback contents; should introduce the gamification; should allow customisation and make adaptive the interaction with users, considering their interaction history, their preferences, requests, needs, and their diversified goals; should propose the tasks decomposed in simple subtasks.

- The language should be simple and precise, and apply the adequate linguistic registers for the target age, supplied as necessary with animations and sounds; acronyms and abbreviations, non-literal texts, and jargon should be avoided.

Furthermore, for what concerns tourism children websites we obviously point out that all the previous suggestions apply as the site should be enjoyable for children. In this context we want to emphasize the key points that we have tested also in our case study that will be presented in Section 3:

1. Providing interesting touristic material targeted for children, i.e., with a short interesting text whose reading creates curiosity and expectations;

2. addition of interactive games containing information related to the target destination.

That is, the site should follow standard children usability rules, but at the same time should create curiosity to visit the tourism destination.

\section{Our Case Study: a Naturalistic Oasis}

$+$

In this section we describe our case study. For a naturalistic oasis called Oasi Cervara, we created a section of the website, called Oasi Kids ${ }^{1}$, designed for the direct navigation by children [9].

The Oasis is situated in in the Veneto Region in the North of Italy and has a special environment composed of a swamp ambient and a peat bog system, and provides habitat for different spices of animals; for this reason is considered by the Veneto Region as Community Interest Site and Special Protection Zone for the fauna of the Sile river.

The Oasi Cervara S.r.l. manages the park trying to combine the protection and conservation of the ambient together with visitors' enjoyment. This park is mainly visited by families (in $79 \%$ of the cases), schools (in $19 \%$ of the cases), photographers (in $2 \%$ of the cases), or elderly people. The Oasis has a certificate of Excellence on TripAdvisor; however the few negative scores indicate that there is a gap between the expectations (e.g., seeing a lot of animals), and what it is really offered (which obviously also depends on the season, the weather, etc.). Thus, improving the quality of the offered information on the website is a

\footnotetext{
${ }^{1}$ Section temporarily offline from the official site http://oasicervara.it/ for technical
} reasons, but part of it is online at this link: http://oasikids.altervista.org/oasi-kids/. 
challenging but important point, and for this reason, we proposed and developed the Oasi Kids section, that has the aim of:

1. being inclusive, usable and accessible for children in the range 8-11 years. The site contains some descriptive parts not suitable for younger users;

2. enriching the online communication of the information about the Oasis;

3 . improving the quality perceived by families and teachers of the offer proposed by the Oasis.

The site has been developed using Wordpress, following the guidelines presented in previous Section 2.2, in order to be inclusive for the chosen target. In particular, regarding accessibility, the site is:

- Responsive: may adapt to mobile phones, to different screens and browsers;

- Perceivable: following the W3C guidelines the language has been specified, and there is alternative text for screen readers;

- Distinguishable: there is a good contrast between the colours of pages and of the text, both inside the menu (black over white), and also inside the standard pages (white over grey/black);

- Compatible: the choice of a standard font Arial and of the font-family sansserif, guarantees the maximal compatibility with all the browsers that may access the site.

Regarding usability:

- Navigation: is simple, the user is directed to a specific page via a menu and the related sub-menu or by clicking big buttons with images and text;

- Structure: very simple and functional;

- Layout and graphics: simple, targeted to young users;

- Home Page: adaptable by proposing different topics to different users;

- Text: the length is medium/short, some words are in a different color to emphasise a concept and to create curiosity;

- Syntax of the content is simple and clear.

Regarding the layout and the navigation, clickable areas, where placed with an image and text. E.g., in Figure 1 there are round clickable areas in a shape of a flower to be more enjoyable by young users. There is also a button "Torna al Menu" (Go back to the menu) to simplify navigation. The depth of the navigation is at most 3 clicks. In Figure 1 we may notice that the text is medium/short, and some words are in a different color recalling the concept, e.g., erba (grass) is in green, etc..

Regarding the content, the arguments have been chosen so to create curiosity, interest to visit the park (e.g., messages such as "did you know that ..."), and at the same time contain precise but simple scientific information (such as the family name of an animal, the physical characteristics, etc.). To simplify the educational experience each animal card contains a pdf version that can be downloaded for pre and post-processing. Moreover, the site proposes educational messages, as shown, e.g., in Figure 1 with the message "If you want to see the animals you should be quiet and careful ...". 

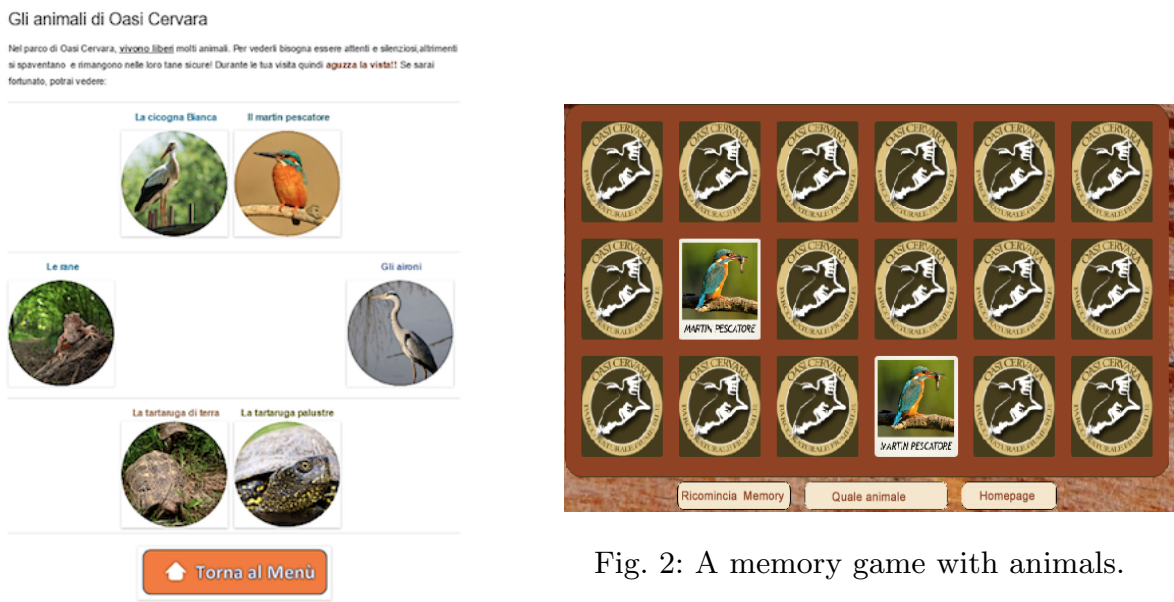

Fig. 2: A memory game with animals.

Fig. 1: Part of a page with animals.

The used language is informal, simple and clear, the description of the animals is in first person. In some parts the text has been written using nursery rhymes, to make the content more enjoyable, musical and memorisable, and also to increase the curiosity of the child for the real visit to the park.

Finally, to improve the navigational and educational experience of the children, the Oasi Kids site proposes two games: a memory game with animal pictures (see Figure 2), and some cards with questions related to the different animals described in the site. To avoid that young users get impatient during the game loading, they are entertained by an animation of an owl that open and closes its eyes.

\section{Experimental results}

In this section we describe the methodology we have used and we then illustrate our experimental results on the Oasi Kids site. We have developed the website following different steps:

- Literature survey: In the first phase, we have collected all the information about usable and accessible websites for young users, and we have defined some features the site should include (e.g., many pictures, games, etc.).

- Interviews: In the second phase, in order to decide how to structure the site and which contents to include, we have conducted two different interviews inside a primary school. The first one with a group of 42 parents of children of the school, the second one with 30 teachers of the school, to check their possible interest for having a website dedicated to children on a tourism educational destination.

Interviews to parents. The three questions were: 
1. The use of technology by children: $90,5 \%$ of the children use by their own technology for games/school research.

2. The search of information for a tourism destination, and the involvement of a child in the search: $100 \%$ of the parents search tourism information on the Web, 55,33\% completely involve their children in the decision, $36,6 \%$ involve them partially.

3. The importance of the development of the Oasi Kids website: The average score was 6 out of 7 .

The parents were also asked about the material they would expect to find in the site, and the major requests were videos and photos (in $84,2 \%$ of the cases), information about the park (in $76,3 \%$ ) and about the flora and fauna (in $71,7 \%$ ). Finally, in $81,6 \%$ of the cases the parents claimed that while choosing between two tourism attractions having the same price, they would pick the one with a website section dedicated to children.

Interviews to teachers. The four questions were:

1. The use of technology by children outside school and at school: Children use technology outside school for games, school research, videos, communication with parents; at school for guided searches on the Web, didactic activities inside educational websites, watching videos dedicated to linguistic and musical activities.

2. The set of activities proposed to children before a tourism didactic experience: Typically teachers try to prepare children to the experience by anticipating them the content of the visit with didactic presentations (37\% of the cases), laboratories (25\%), etc., and the way they should behave. This, in their opinion, increases the quality of the educational experience.

3. The best pre-visit information tool: Technological tools with videos (24 out of 30 teachers), information material (27 out of 30), games (20 out of 30), etc. So all the teachers claimed they would use a site with such a content to prepare children to the visit, and 2 teachers out of 30 stated they would also use it as a post-processing tool after the visit, to let the students internalise and deepen the contents.

4. The importance of the development of the Oasi Kids website: $93 \%$ of the teachers claimed it would improve the quality of the didactic experience.

To conclude, for both interviews emerges the great importance of developing a dedicated website containing videos, photos, didactic material, and games.

- Website development: The third phase was the development of the website applying the usability and accessibility guidelines discussed in Section 2.2, and the hints and suggestions collected in the literary survey and interview phases.

- Assessment questionnaire: In order to evaluate the perceived impression of the Web site, in the last phase we collected through an assessment questionnaire the opinions from a set of 50 parents and separately from a set of 50 children of an age between 8 and 11 years.

The questionnaires for the parents had scores that ranged from 1 to 7 , for children we have used a different scale composed of 4 different emoticons (representing the perception of: very good, good, so and so, do not like). The 
main results of the questionnaire proposed to the parents are summarised in Table 2, more details may be found in [9]. Regarding the questionnaire proposed to the children, the results are summarised in Table 3: The children liked the site in general, liked colours and images, the descriptions and they all would be exited to visit the Oasis.

Table 2: Results of the assessment questionnaire proposed to 50 parents.

\begin{tabular}{|l|c|}
\hline QUESTIONS & Average grade \\
\hline Do you like the Oasi Kids site? & $5.6 / 7$ \\
\hline Do you like the site content? & $5.62 / 7$ \\
\hline Do you like the site information? & $5.54 / 7$ \\
\hline Do you like the site colours and characters? & $5.4 / 7$ \\
\hline Was the quality of the tourism destination increased by the website? & $4.9 / 7$ \\
\hline
\end{tabular}

Table 3: Results of the assessment questionnaire proposed to 50 children.

\begin{tabular}{|c|c|c|c|c|}
\hline QUESTIONS & $\approx 0$ & 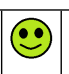 & $\ddot{\ominus}$ & \\
\hline Do you like the Oasi Kids site? & 20 & 23 & 7 & - \\
\hline Do you like colors and images? & 23 & 22 & 3 & 2 \\
\hline Was it easy to find the material you searched for? & 14 & 26 & 10 & - \\
\hline Were the topic descriptions interesting? & 22 & 20 & 6 & 2 \\
\hline Do you feel like visiting the Oasis now? & 20 & 25 & 5 & - \\
\hline
\end{tabular}

To conclude, the parents and the children have in general appreciated the website Oasi Kids and, although some time is needed to have a real feedback, in our opinion this could be a good starting point for the increment of visits to the Oasi Cervara park.

\section{Conclusion and Future Challenges}

In this paper, we analysed how tourism websites should be developed to be usable and accessible by children. We have shown how a child that enjoys the navigation on a site may influence the choice of a particular tourism destination by the whole family or by a school for didactic purposes. We have illustrated an interesting U\&A children tourism website that we have developed following the proposed usability and accessibility guidelines, and we have discussed in details the result of an assessment questionnaire proposed to parents and to children, that shows how the site was well appreciated by both groups.

As a future work we are developing another tourism website on which we are planning to do a more extensive analysis by considering features such as users (children) experience, improved experience, increased number of visits or longer sessions. We also plan to propose a set of templates and widgets conceived specifically for tourism websites. 


\section{References}

1. I leoni del tempo. (2017), Tourism app for children. https://goo.gl/HBsfSb

2. Ahluwalia, R.: The 50 best travel websites (2017), Indipendent - https://goo.gl/ cr3XK7

3. Art Stories: Journey Journal (2017), http://www .artstories.it

4. Bernhardt, G.: Designing Usable Sites for Children and Teens (2006), https:// $\mathrm{msu}$. edu/user/webbsuza/atw/graceb/

5. Dattolo, A., Luccio, F.L.: A review of websites and mobile applications for people with autism spectrum disorders: Towards shared guidelines. In: Lecture Notes of the Institute for Computer Sciences, Social-Informatics and Telecommunications Engineering, LNICST - 195. pp. 264-273. Springer Verlag (2016)

6. Dattolo, A., Luccio, F.L.: Accessible and usable websites and mobile applications for people with autism spectrum disorders: a comparative study. EAI Endorsed Transactions on Ambient Systems 4(13) (2017)

7. Dattolo, A., Luccio, F.L., Pirone, E.: Web accessibility recommendations for the design of tourism websites for people with autism spectrum disorders. International Journal on Advances in Life Sciences 8(3-4), 297-308 (2016)

8. De Cock, R. and Hautekiet, E.: Childrens news online: content analysis and usability study results (2011), https://goo.gl/FLSb8Z

9. De March, C.: La personalizzazione dei contenuti Web per migliorare l'attrattività delle imprese turistiche e culturali: il caso di studio di Oasi Cervara. Master's thesis, Università Ca' Foscari, Venezia (2016), https://goo.gl/5dAgzH

10. Ducan, A.: Educational websites for kids that are free (2017), the spruce https://www.thespruce.com/best-free-educational-websites-for-kids-3129084

11. Erikson Institute: Technology and Young Children in the Digital Age. (2016), https://goo.gl/hZSQCw

12. Influence Central: Kids \& Tech: The Evolution of Today's Digital Natives (2016), https://goo.gl/6K8NgW

13. Large, A., Beheshti, J., Rahman, T.: Design criteria for children's web portals: The users speak out. Journal of the American Society for Information Science and Technology 53(2), 79-94 (2002)

14. Loranger, L., Nielsen, J.: Teenage usability: Designing teen-targeted websites (2013), https://goo.gl/81zY58

15. Nielsen, J.: Children's websites: Usability issues in designing for young people (2010), https://goo.gl/D5q35b

16. Seeman, L., Cooper, M.: Techniques for the the cognitive and learning disabilities accessibility task force (coga) (2016), W3C, https://goo.gl/bdKhQi

17. Srnec, T., Lončarić, D., Perišić Prodan, M.: Family vacation decision making process: evidence from Croatia. In: Proceedings of the Congress on Tourism \& Hospitality Industry. pp. 432-445. Opatija, Croatia - Hrvatska (April, 28-29 2016)

18. UxKids: Comparing Usability for Kids and Adults (Part 1) (2013), http://uxkids . com/blog/comparing-usability-for-kids-and-adults-part-1/

19. Vukovi, K., Librenjak, S., Dovedan, Z.: Internet for the youngest: Computer usage and web design for the early school age children. International Journal of Emerging Technologies in Learning 5(S12), 17-23

20. WAI: Accessibility, usability, and inclusion: Related aspects of a web for all (2016), https://www.w3.org/WAI/intro/usable

21. White, B.: Designing For Kids Is Not Childs Play (2016), https://goo.gl/nYx9bK 